\title{
Effect of Fly ash on Strength Characteristics of Roller Compacted Concrete Pavement
}

\author{
S.Pavan ${ }^{1}$, S. Krishna Rao ${ }^{2}$ (Associate Professor) \\ ${ }^{I}$ (Department of Civil Engineering, VR Siddhartha Engineering College, Vijayawada, India) \\ ${ }_{2}^{2}$ (Department of Civil Engineering, VR Siddhartha Engineering College, Vijayawada, India)
}

\begin{abstract}
In this paper the behaviour of roller compacted concrete pavement with fly ash is examined. In the preparation of fly ash roller compacted concrete (FRCC), the maximum aggregate size was $20 \mathrm{~mm}$ in all of the mixtures which were designed using maximum density method. The cement content of the control mixture was $318 \mathrm{~kg} / \mathrm{m}^{3}$. Cement was replaced at various percentage levels such as $20 \%, 40 \%$, and $60 \%$ besides control concrete was also prepared for comparison purpose. Compressive strength, split tensile strength, flexural strength were determined at 3,7 and 28 days. Test results indicate that the mixtures where cement was substituted with fly ash, increasing the fly ash content caused reduction in compressive, splitting tensile and flexural strength values at all of the ages up to 28days.
\end{abstract}

Keywords: RCCP, Mix Design, Strength, Cement content, w/c Ratio, admixtures

\section{Introduction}

Roller compacted concrete (RCC) is a dry mixture of coarse aggregates, fine aggregates, cement and water compacted by vibratory rollers (ACI Committee 325,1995)[1]. The use of RCC for pavements is relatively a new technology and is still under development. The first RCCP was constructed in Canada in 1976 at the logsorting yard at Caycuse on Vancouvar island, by the British Colombia forest company (BCFP) where 4 acres of RCCP were constructed and then was doubled in 1978 expansion[2]. Following this success, several projects utilising RCCP were constructed in America, Spain , Australia and elsewhere[1,2,3]. RCC is a friendly pavement material in which incorporated by products from industries. Its use in RCC can be achieved by directly adding these materials to the mixture proportions, or by replacing fine mineral aggregate content.

Fly ash (FA) is the residue collected from burning smoke flue. The main useful effect of FA in concrete consists of three aspects, often called morphologic effect. The morphologic effect states that there are many micro beads in FA working as "lubricating balls" when incorporated in fresh concrete. Hence it benefits the fluidity .The micro aggregate effect of FA states that micro beads in FA can disperse well in concrete and combined firmly with gel produced in cement hydration and thus promote concrete density.[4]Various mineral admixtures such as fly ash are used in order to improve some mechanical and physical properties of concrete and to reduce its cost .Fly ash is obtained as a waste product during the combustion of pulverized coal in thermal power plants. Fly ash is used as an admixture in cement and concrete because of its pozzolanic and/or self cementitious nature.The effect of fly ash on the mechanical properties of RCC mixtures was studied by several investigators. The influence of high amounts of fly ash used in roller compacted concrete on compressive and flexural strengths has been investigated by Cao et a[5]1. In this study $45-95 \mathrm{wt} \%$ of cement was replaced with fly ash in ' six different proportions. The cement content of the control mix was $300 \mathrm{~kg} / \mathrm{m}^{3}$, It was observed that there was a decrease in strength at early ages and an increase in strength at later ages while the amount of fly ash increased from $0 \%$ to $55 \%$. Increase in the amount of fly ash from $55 \%$ to $95 \%$ in the mixture caused strength loss at both early and later ages.

\section{Materials And Method}

\section{1 .Materials Used In The Reesearch}

1)Cement: Ordinary Portland cement (OPC )53grade confirming to Indian standard IS : 12269(1987) was used for the present experimental investigation. It is specific gravity is 3.15 . The cement was tested as per the procedure given in Indian standard IS 4031(1988)

2) Fine aggregate: Natural river sand confirming to zone III as per IS: 383(1987) was used .The specific gravity is 2.65

3) Coarse aggregate: Crushed granite coarse aggregate confirming to IS:383(1987) was used .Coarse aggregate of size $20 \mathrm{~mm}$ down having the specific gravity of 2.87 was used.

4) Class F fly ash obtained from Dr.N.T.T.P.S,Ibrahim patanam was used.Its specific gravity is 2.20 


\subsection{Mix Designing Method}

The method employed for mix design is derived from the soil compaction method, and is based on the relationship between bulk density of the dry mixture and the moisture content of RCC. Mix was designed as per ACI 211-3R-19 guide lines. In this method a series of mixture for each cementitious materials content is prepared and batched using a range of water contents. Each prepared mixture is compacted with modified proctor's effort. The maximum density and optimum water content are determined from a plot of density vs. water content for the compacted specimens at each cementitious material content. RCC specimens are made at the OMC (Optimum Moisture Content).

\section{1 casting Of Beams}

\section{Test Procedure}

The dimensions of all the specimens are identical. The length of beams was $500 \mathrm{~mm}$ and the cross sectional dimensions were $100 \mathrm{~mm} \times 100 \mathrm{~mm}$. The beams were casted and de-moulded after one day and are allowed to cure in water.

\subsection{Casting Of Cubes}

The dimensions of all the specimens are identical. The length, width and depth of the cubes are $150 \mathrm{~mm}$. The cubes were casted and de-moulded after one day and are allowed to cure in water.

\subsection{Casting Of Cylinders}

150x300mm cylinders for split tensile strength . The cylinders were casted and de-moulded after one day and are allowed to cure in water

\subsection{Testing Of Specimens}

The compressive strength,Split Tensile strength,Flexural strength of $150 \mathrm{~mm}$ cube, $300 \times 150 \mathrm{mmcylinder}, 100 \times 100 \times 500 \mathrm{~mm}$ prism specimens respectively were obtained at 3,7 , and 28 days ages in accordance with IS:516-1959standard.

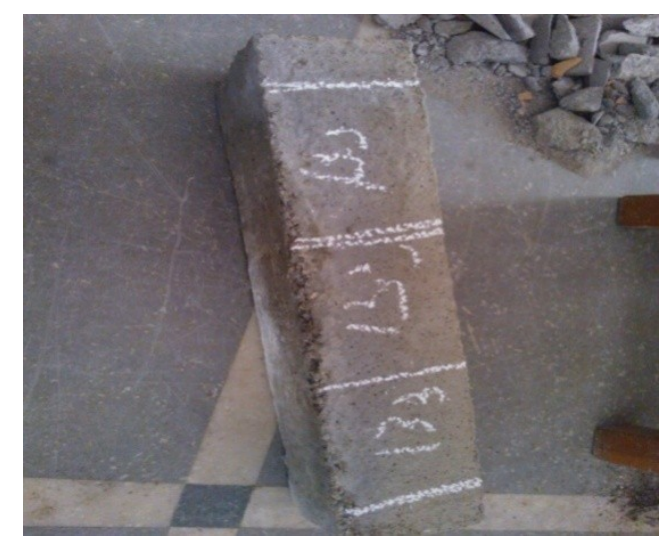

Casted beam

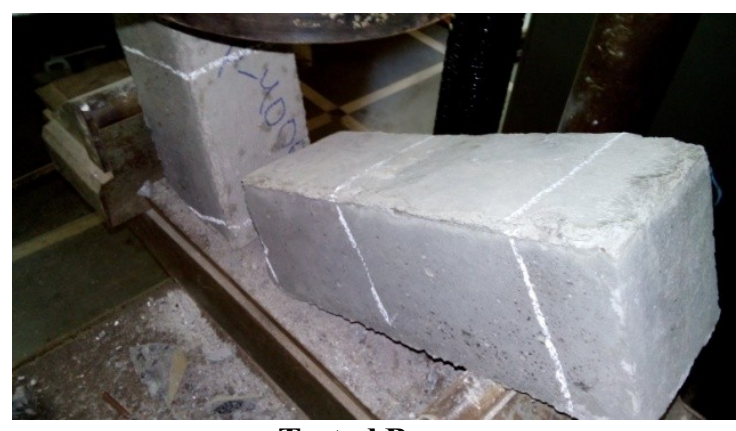

Tested Beam

\section{Test Results \& Discussion}

The strength tets results are presented in table 2,3,and 4.It seen that the minimum strength results at all ages belong to the mixture where $60 \%$ of the cement is replaced with fly ash. The reduction in strengths is higher at 7-day age specimens. The reduction in strngth of mixture is due to fact that the contribution of fly ash 
to the strength of concrete is lower than that of cement even up to 28days.However, owing to the pozzolonic reaction of fly ash the difference between the strength of control mixture and fly ash containig mix decreased by time

Table1:Mixing proportions of FRCCin $\mathrm{kg}$ per one $\mathrm{m}^{3}$ of concrete

\begin{tabular}{|c|c|c|c|c|c|c|}
\hline $\mathbf{M}$ & F A & $\mathbf{C}$ & $\mathbf{W}$ & $\mathbf{R S}$ & $\mathbf{C A}$ & W/cm \\
\hline$F_{0}$ & $\mathbf{0}$ & $\mathbf{3 1 8}$ & $\mathbf{9 2 . 1}$ & $\mathbf{8 7 2}$ & $\mathbf{1 3 1 6}$ & $\mathbf{0 . 2 8}$ \\
\hline $\mathrm{F}_{20}$ & $\mathbf{6 3}$ & $\mathbf{2 5 4}$ & $\mathbf{1 1 6 . 3}$ & $\mathbf{8 4 0 . 6}$ & $\mathbf{1 2 6 7 . 8}$ & $\mathbf{0 . 3 7}$ \\
\hline $\mathrm{F}_{40}$ & $\mathbf{1 2 7}$ & $\mathbf{1 9 0}$ & $\mathbf{1 3 7 . 2}$ & $\mathbf{8 1 4 . 0}$ & $\mathbf{1 2 2 7 . 6}$ & $\mathbf{0 . 4 6}$ \\
\hline $\mathrm{F}_{60}$ & $\mathbf{1 9 0}$ & $\mathbf{1 2 7}$ & $\mathbf{1 4 1 . 4}$ & $\mathbf{8 0 3 . 1}$ & $\mathbf{1 2 1 1 . 3}$ & $\mathbf{0 . 4 8}$ \\
\hline
\end{tabular}

M:Mix ; FA:Fly ash; W:Water; RS:Rive Sand; CA:Coarse Aggregae; W/cm: Ratio of water to Cementitious material

Table2:Split tensile strength test resuls $\left(\mathrm{N} / \mathrm{mm}^{2}\right)$

\begin{tabular}{|c|c|c|c|c|}
\hline Mix & F0 & F20 & F40 & F60 \\
\hline Fly ash (\%) & 0 & 20 & 40 & 60 \\
\hline Test age (days) & \multicolumn{5}{|c|}{ Split tensile stregth(Mpa) } \\
\hline 3 & 1.56 & 1.55 & 0.77 & 0.14 \\
\hline 7 & 2.28 & 1.98 & 1.55 & 0.42 \\
\hline 28 & 4.02 & 5.30 & 3.18 & 1.69 \\
\hline
\end{tabular}

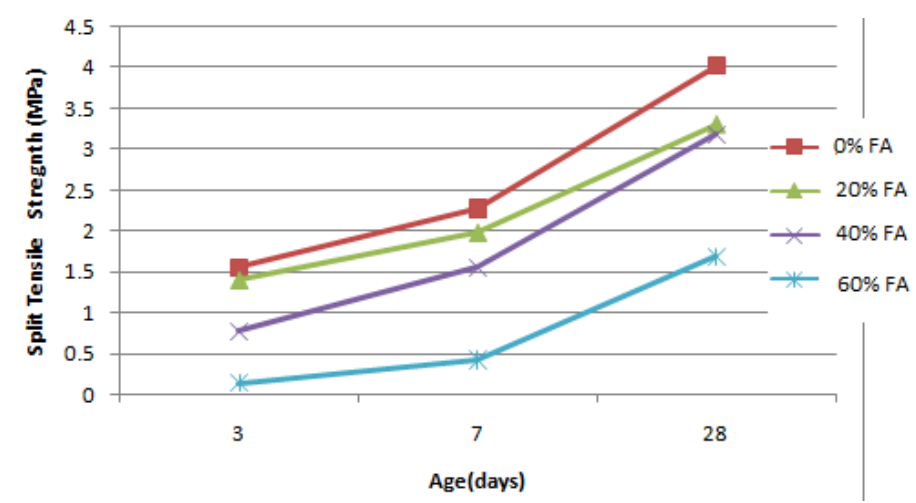

Fig 1.Split tensile strength versus age(days)

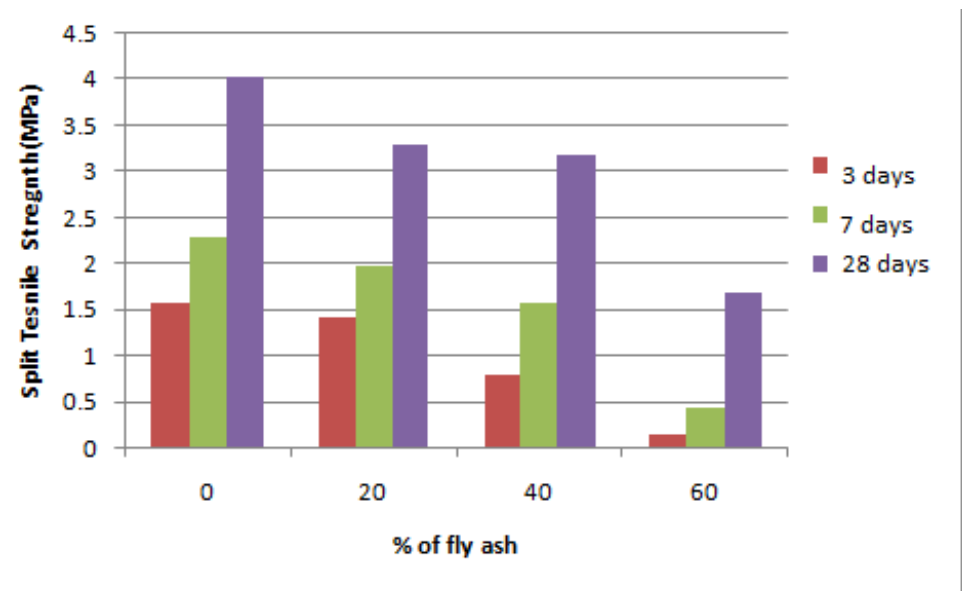

Fig 2.Split tensile strength versus flyash percentage 
Table 3: Compressive strength

\begin{tabular}{|c|l|l|l|l|}
\hline Mix & F0 & F20 & F40 & F60 \\
\hline $\begin{array}{c}\text { Fly ash } \\
(\%)\end{array}$ & 0 & 20 & 40 & 60 \\
\hline $\begin{array}{c}\text { Test age } \\
\text { (days) }\end{array}$ & \multicolumn{5}{|l|}{} \\
\hline 3 & 18.67 & 16.89 & 11.55 & 3.99 \\
\hline 7 & 22.22 & 20.00 & 16.44 & 8.88 \\
\hline 28 & 33.74 & 29.78 & 24.00 & 16.00 \\
\hline
\end{tabular}

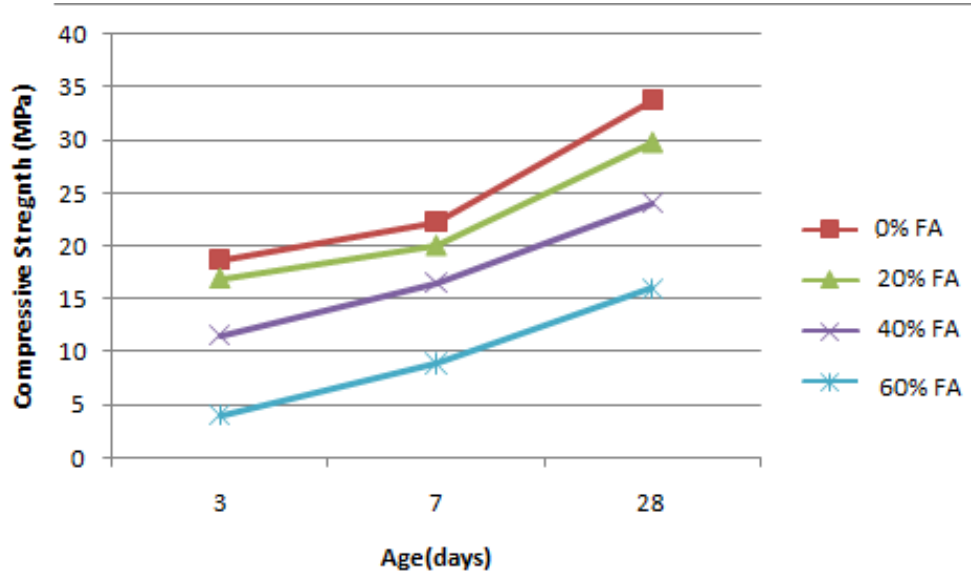

Fig 3.Compressive strength versus age

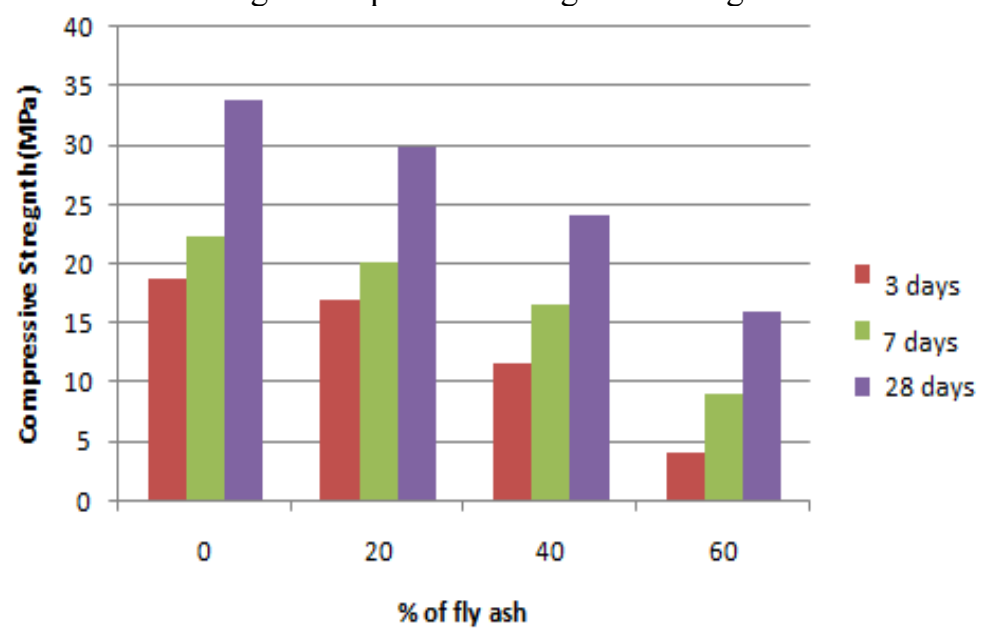

Fig4.Compressive strength versus flyash percentage

Table4:Flexural strength

\begin{tabular}{|l|l|l|l|l|}
\hline Mix & F0 & F20 & F40 & F60 \\
\hline Fly ash (\%) & 0 & 20 & 40 & 60 \\
\hline $\begin{array}{l}\text { Test age } \\
\text { (days) }\end{array}$ & \multicolumn{5}{|l|}{} \\
\hline 3 & 3.8 & 3.4 & 3.2 & 0.4 \\
\hline 7 & 4.4 & 4.4 & 4.0 & 2.2 \\
\hline 28 & 6.8 & 7.1 & 5.4 & 4.2 \\
\hline
\end{tabular}




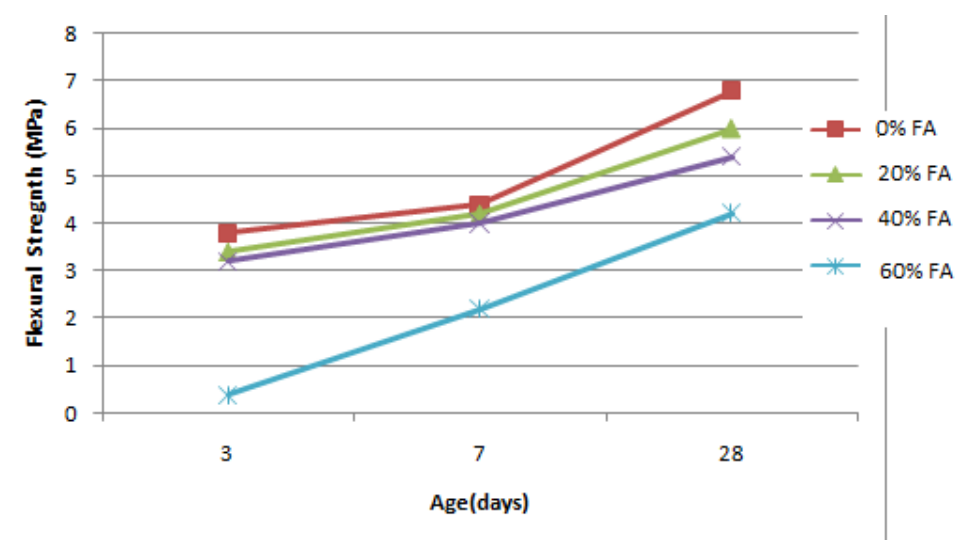

Fig 5.Flexural strength versus age

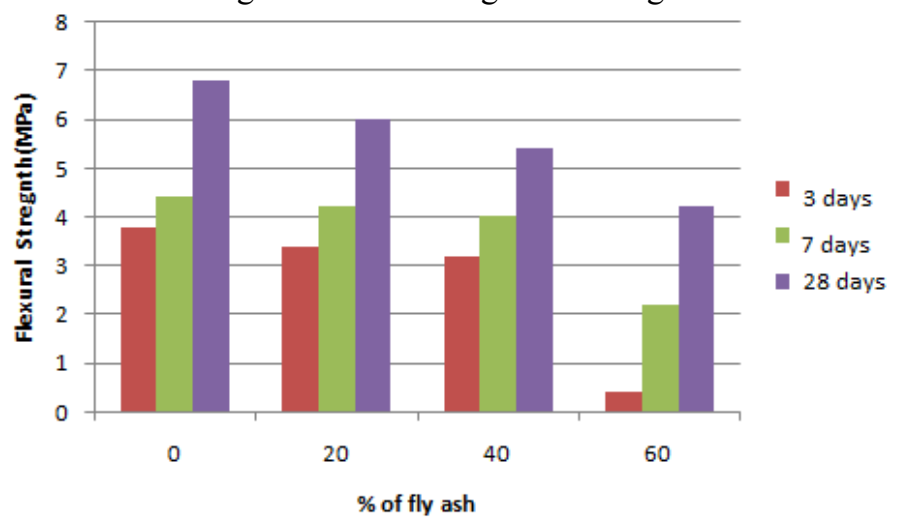

Fig 5.Flexural strength versus percentage of fly ash

\section{Conclusion}

For the materials used and test methods applied the following conclusions can be drawn

When increasing the fly ash content and increse in water cement ratio to the mixture the unit weight of mix sdecreases.

In mixtures where cement was partially replaced with fly ash, strength values were decreased with increasing fly ash content. The effect, in part,was attributed to the increase in water/binder ratio of the mix due to fly ash addition and in part to the lower contribution of fly ash than cement to strength even up to 28days.

When replacing $60 \%$ fly ash with the cement it causes to reduction in 7-day strength and the mix gains only $50 \%$ of its 28 -days strength.However, at later ages the rate of strength of mix increases and very close to each other and independent of fly ash content of the mix.

\section{References}

[1]. ACI 325 10R-95,state-of-the-Art report on roller compactedconcrete pavements, ACI manual of concrete practice, ACI,USA, 2000:32PP

[2]. R Piggot, Roller compacted concrete for heavy dutypavement:past performance, Recent projects and recommended constructed methods, TRR 1062, NationalResearch Council , Washington ,DC,1986,pp7-12

[3]. Hisham Y Qasrawi, Ibrahim M AsiH.I.Al-AbdualWahhab, Proportioning RCCP mixes under hot weather conditions for a specified tensile strength, cement and concrete research, 35(2005) 267-276.

[4]. Ali Mardani-Aghabagolu,Kambiz Ramyar (2013),Mechanicall properties of high volume flyash roller compacted concrete designed by maximum dr density method Construction and building materials 38(2013)356-364

[5]. Cheng Cao,Wei sun,Honggrn Qin, The analysis on Strength and fly ash effect of roller compacted concrete with high volume fly a sh

[6]. S.KrishnaRao, Dr.T.ChandraSekharRao, Dr.P.Sravana"Effect of Manufacture sand on Strength Characteristics of Roller Compacted Concrete”, International Journal of Engineering Research \& Technology (IJERT) Vol. 2 Issue 2, February - 2013

[7]. S.KrishnaRao,Dr.T.ChandraSekharRao,Dr.P.Sravana, "Mix Design of Roller Compacted Concrete: An experimental Study Using Crushed Stone and River Sand as Fine Aggregate" National Conference on SCMAT, NIT Warnagal, 2013

[8]. IS:516-1959, "Indian standard code of practice-methods of test for strength of concrete",Bureau of Indian standards,New Delhi.India. 